\title{
Evidence of a Genomic Biomarker in Normal Human Epithelial Mammary Cell Line, MCF-10A, That Is Absent in the Human Breast Cancer Cell Line, MCF-7
}

\author{
Brian H. Crawford, AKM A. Hussain, and Nathan M. Jideama \\ Department of Biological Sciences, Clark Atlanta University, 223 James P Brawley Drive, Atlanta, GA 30314, USA
}

Received 21 November 2005; Accepted 5 April 2006

This study investigated the use of DNA amplification fingerprinting (DAF) to identify biomarkers useful in the elucidating genetic factors that lead to carcinogenesis. The DNA amplification fingerprinting (DAF) technique was used to generate fingerprint profiles of a normal human mammary epithelial cell line (MCF-10A) and a human breast cancer cell line (MCF-7). When compared with one another, a polymorphic biomarker gene (262 base pairs (bps)) was identified in MCF-10A but was not present in MCF-7. This gene was cloned from the genomic DNA of the MCF-10A cell line, and subjected to Genbank database analysis. The analysis of the nucleotide sequence polymorphic marker (Genbank account: AC079630) shows that this biomarker has 100\% homology with the nucleotide sequence of human chromosome 12 BAC RP11-476D10 (bps 19612-19353). The nucleotide sequence was used for possible protein translation product and the result obtained indicated that the gene codes for hypothetical protein XF2620. In order to evaluate the effects that the 262 bps biomarker would have on the morphology of MCF-7 cells, it was transfected into MCF-7 cells. There were observable changes in the morphology of the transfected cells. These changes included an increase in cell elongation and a decrease in cell aggregation.

Copyright (c) 2006 Brian H. Crawford et al. This is an open access article distributed under the Creative Commons Attribution License, which permits unrestricted use, distribution, and reproduction in any medium, provided the original work is properly cited.

\section{INTRODUCTION}

DNA "fingerprinting" has been used for genome linkage, genetic variation, population and pedigree analysis, forensic identification, localization of disease loci, and epidemiology [1-3]. Variation in the nucleotide sequence of DNA has been exploited to produce characteristic fingerprinting because of its plasticity, ubiquity, and stability [4-6].

Cancer cells typically possess hundreds and even thousands of genomic errors, and unique patterns of genetic mutations are found in virtually every different tumor $[7,8]$. Unlike classical genetic diseases, there are no well-defined correspondences between the genetic mutations present in cancer populations and the cellular characteristics of the malignant phenotype [9].

The most common form of cancer among women is breast cancer [10]. Although it is the second leading cause of mortality among females, the pathogenesis of the disease remains unclear $[11,12]$. Most mutations in human malignancies were identified by conventional methods such as single-strand conformational polymorphism (SSCP) and DNA sequencing [13]. Other methods, such as denaturing gradient gel electrophoresis, heteroduplex analysis, and cleavage methods [14] have also been used. All these methods are relatively time-consuming, labor intensive, and sequential processes.

The amplification fragment length polymorphism AFLP involves the enzymatic amplification of template DNA directed by one or more arbitrary oligonucleotide primers to produce a characteristic spectrum of products, a part of which could be polymorphic. The procedure is fast, independent of prior genetic and biochemical knowledge of the organism tested, and allows tailoring of the number of products and polymorphisms generated [15]. DNA amplification fingerprinting (DAF) is one of the best technological developments due to its use of the simplest and most relaxed amplification conditions and the shortest primers, and offering high resolution. DAF is based on the principle that DNA from two different sources has different distributions of specific DNA sites. The DNA at these sites can be cut with restriction nucleases producing a unique set of DNA fragments from the entire genome of the organism. The DAF technique can be accomplished by sorting these fragments by size using SDSpolyacrylamide gel electrophoresis [4]. 
Breast cancer and other malignancies result from stepwise genetic alternations of normal host cells. Genome instability promotes great potential to develop genetic changes such as gene loss, gene amplification, point mutation, and chromosomal translocations [16]. In regards to breast cancer, loss of heterozygosity (gene loss) and changes in gene copy number cause the development and progression of the disease $[17,18]$.

In the present investigation, we used the DAF technique in the identification of a polymorphic gene present in normal human mammary epithelial cell line, MCF-10, but absent in human breast cancer cell line, MCF-7.

\section{MATERIALS AND METHODS}

\section{Cell lines}

Normal human breast epithelial cells (MCF-10A) and human breast cancer cells (MCF-7) used for this study were obtained from the ATCC (Manassas, Va) company.

\section{Isolation of genomic DNA and generation of fingerprinting profile}

DNAzol genomic DNA isolation reagent (Molecular Research Center, Inc, Cincinnati, Ohio) was used to isolate the genomic DNA of human mammary epithelial cell line (MCF$10 \mathrm{~A})$ and breast cancer cell line (MCF-7). DNA amplification was performed by using a solution $(25 \mu \mathrm{L})$ containing $2 \mathrm{ng}$ of template DNA, 0.3 units/ $\mu$ L of Amplitaq DNA polymerase (Stoffel fragment) from Thermus aquaticus (PerkinElmer/cetus, Norwalk, Conn, USA), $200 \mu \mathrm{M}$ of each deoxynucleotide triphosphate (Pharmacia LKB Biotechnology Inc, Piscataway, NJ, USA), $6 \mathrm{mM} \mathrm{MgCl}_{2}, 10 \mathrm{mM}$ Tris- $\mathrm{HCl}$ ( $\mathrm{pH} 8.3$ ), and $10 \mathrm{mM} \mathrm{KCl}$. The solution also contained $0.3 \mu \mathrm{L}$ of DAF arbitrary primer (8-10 nucleotides in length) that required low stringency cycles to amplify DNA polymorphism [19]. Due to the fact that there was no known evidence of which primers would yield polymorphic products, 10 DAF primers from each of the 4 series (A, B, C, and D; totaling forty primers) were randomly selected and used for both MCF-10A and MCF-7 cell lines. Out of these 40 DAF primers, only one (A25 (GCCCGTGC)) yielded polymorphic markers in three separate experiments, giving evidence of reproducible results. The remaining 39 DAF primers did not yield any polymorphisms. The solution was overloaded with two drops of mineral oil and the samples were amplified in an Ericomp thermocycler (Ericomp Inc, San Diego, Calif, USA) for 35 two-step cycles of 1 second at $96^{\circ} \mathrm{C}$ and 1 second at $30^{\circ} \mathrm{C}$. The heating and cooling rates of the thermocycler were $23^{\circ} \mathrm{C} / \mathrm{min}$ and $14^{\circ} \mathrm{C} / \mathrm{min}$, respectively. $3 \mu \mathrm{L}$ of the amplification reaction was loaded with $3 \mu \mathrm{L}$ of loading buffer (5 M urea, 3\% ficoll, $0.12 \%$ Tris, 1.12\% EDTA, 0.02\% xylene cyanol, and $0.02 \%$ bromophenol blue). Polyacrylamide gel electrophoresis $[4,15]$ was used to separate DNA amplification fragments. Electrophoresis was run at $100 \mathrm{~V}$, until the dye front was approximately $1 \mathrm{~cm}$ from the end of the gel. A silver staining procedure [15] that detects $1 \mathrm{pg} D \mathrm{DNA} / \mathrm{mm}^{2}$ band cross-section was used to observe DNA. The gels were permanently preserved using polyester-backed gels by soaking in 50\% ethanol for 10 minutes and drying at room temperature.

\section{Isolation and cloning of biomarker sequence}

The polymorphic band was excised from the wet polyacrylamide gel and submerged in $20 \mu \mathrm{L}$ of TE buffer $(10 \mathrm{mM}$ Tris, $1 \mathrm{mM}$ EDTA). The mixture was heated for $20 \mathrm{~min}-$ utes at $90^{\circ} \mathrm{C}$ and stored at $4^{\circ} \mathrm{C}$ for 2 days. Two $\mu \mathrm{L}$ of the mixture was used for the DAF PCR reaction with DAF arbitrary primer, A25. Three $\mu \mathrm{L}$ of the PCR product was ligated into pCR II and transformed into one-shot competent cells (according to the procedure of TA cloning kit dual promoter (pCR II), Invitrogen Life Technology, Carlsbad, California, USA-version H). A white color on LB plates (1.0\% tryptone, $50 \mu \mathrm{g} / \mathrm{mL}$ ampicillin, $0.5 \%$ becto-yeast extract, $1.0 \% \mathrm{NaCl}$, and $0.15 \%$ agar) identified the colonies that contained the fragment, which was generated using $X$ gal due to the expression of the lac promoter of the pCR II vector. Individual white colonies of the polymorphic band were digested by EcoRI restriction enzyme and run on a $1 \%$ agarose gel stained with ethidium bromide $(0.5 \mu \mathrm{g} / \mathrm{mL})$. The gel was viewed under UV light to identify the bands that contained the fragment. The expected colonies were grown in LB medium ( $1 \%$ tryptone, $0.5 \%$ yeast extract, $1 \% \mathrm{NaCl}$, ampicillin antibiotic $(50 \mu \mathrm{g} / \mathrm{mL})(\mathrm{pH} 7.0))$ over night at $37^{\circ} \mathrm{C}$ on electrical shaker at $225 \mathrm{rpm}$. The plasmid DNA was purified by the Wizard Plus Miniprep DNA purification system (Promega Corporation, Madison, Wisconsin, USA). The purified plasmid DNA was sequenced by DNA sequencer (ABI Prism, Model 3100, Version 3.7) at Morehouse School of Medicine in Atlanta, Georgia, USA.

\section{TRANSFECTION OF MCF-7 CELLS}

Two $\mu g$ of the isolated 262 bps DNA fragment were added to $100 \mu \mathrm{L}$ of OPTI-MEM medium. This mixture was combined with $10 \mu \mathrm{L}$ of CELLFECTIN reagent in $100 \mu \mathrm{L}$ OPTIMEM medium. The combined mixture was gently mixed and incubated at room temperature for 30 minutes. The incubated mixture was carefully overlaid over the MCF-7 cells ( 2 to $3 \times 10^{5}$ cells in $4 \mathrm{~mL}$ of growth medium supplemented with serum) and incubated for 24 hours in a $\mathrm{CO}_{2}$ incubator [20]. The transfection mixtures were washed with $2 \mathrm{~mL}$ of serum-free growth medium without antibacterial agents. Then $1.8 \mathrm{~mL}$ serum-free growth medium was added to each tube containing CELLFECTIN reagent-DNA complexes, mixed gently, and overlaid onto the cells. The cells were incubated for 24 hours at $37^{\circ} \mathrm{C}$ in a $\mathrm{CO}_{2}$ incubator. The DNA-containing medium was replaced with $4 \mathrm{~mL}$ of growth medium (supplemented with serum) and the cells were incubated at $37^{\circ} \mathrm{C}$ in a $\mathrm{CO}_{2}$ incubator for another 48 hours. The cells were trypsinized and the genomic DNA of the transfected MCF-7, untransfected MCF-7 (control), and MCF$10 \mathrm{~A}$ (control) cells were isolated using DNAzol genomic DNA isolation reagent. DNA amplification fingerprinting 


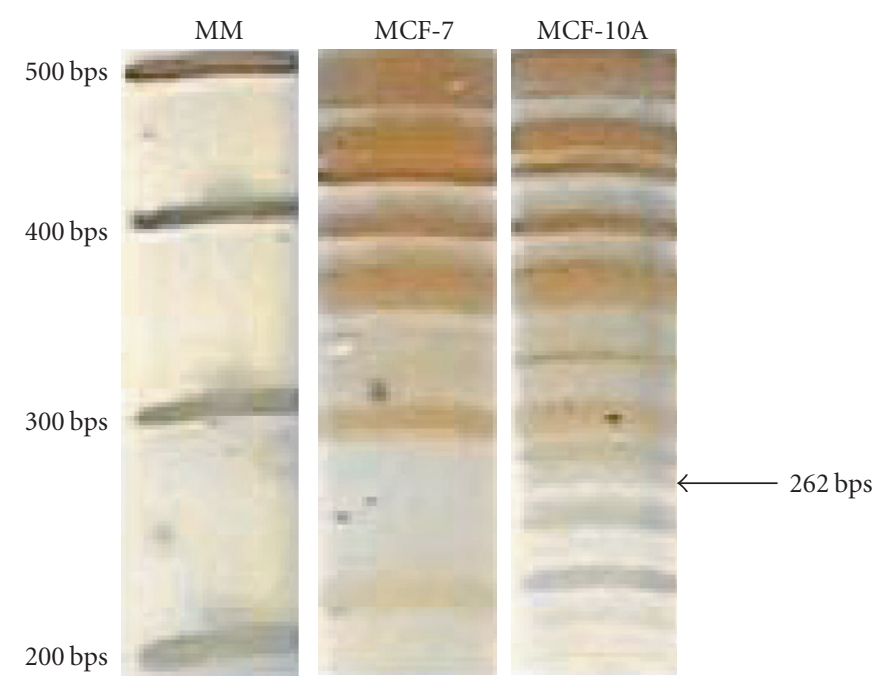

FIGURE 1: DNA amplification fingerprintings of breast cancer cell (MCF-7) and human mammary epithelial cell (MCF-10A). Three $\mu$ L of the DAF PCR amplification reaction mixture was loaded with $3 \mu \mathrm{L}$ of loading buffer. Electrophoresis was continued at $100 \mathrm{~V}$ until the dye front was approximately $1 \mathrm{~cm}$ from the end of the gel. The amplification fragments were separated by polyacrylamide gel (5\%) electrophoresis. DNA was visualized using a fast and sensitive silver staining procedure that detects $1 \mathrm{pg}$ DNA/mm band cross-section. The polymorphic marker was found at 262 bps. These results were confirmed by three additional experiments.

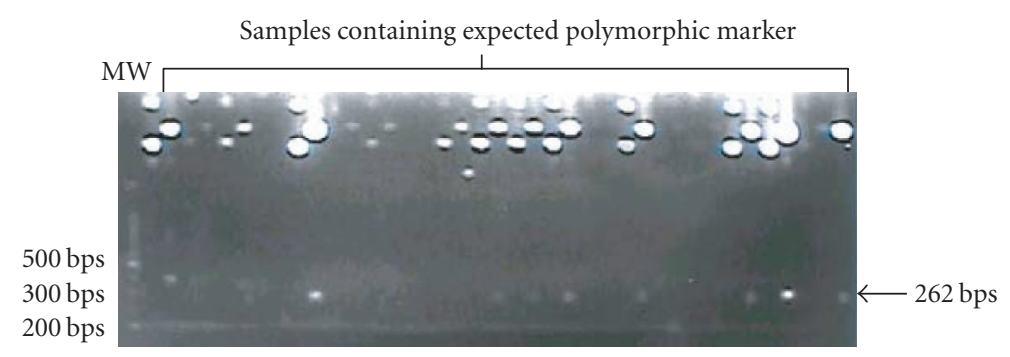

FIGURE 2: Restriction mapping of the plasmid containing the expected polymorphic marker. The DNA of 30 individual colonies having the expected polymorphic marker was extracted by the DNAzol extraction method. The DNA $(4 \mu \mathrm{L})$, restriction enzyme (EcoRI, $20 \mathrm{U} / \mathrm{mL})$ $(1 \mu \mathrm{L})$, buffer $(10 \mathrm{X})(2 \mu \mathrm{L})$, and water $(13 \mu \mathrm{L})$ were mixed together. The reaction mixture was incubated at a $37^{\circ} \mathrm{C}$ for 2 hours in a water bath. $15 \mu \mathrm{L}$ of reaction mixture with $1 \mu \mathrm{L}$ of loading buffer was loaded into a $1.0 \%$ agarose gel, stained with ethidium bromide $(0.5 \mu \mathrm{g} / \mathrm{mL})$, and viewed under UV light. These results were reproduced in three supplementary experiments.

was performed as mentioned earlier and the cell counts were performed using Axiovert-25 inverted microscope (Software: Axiovision 4.0).

\section{Results}

The DNA amplification fingerprinting (DAF) technique was used to generate fingerprint profiles of a normal human mammary epithelial cell line (MCF-10A) and a human breast cancer cell line (MCF-7). When compared with one another, a polymorphic biomarker gene (262 bps) and others were identified in MCF-10A but were not present in MCF7 (Figure 1). Although there were other biomarker genes present, this study focuses only on the $262 \mathrm{bps}$ biomarker. The other biomarkers will be subjected to further studies.

The 262 bps biomarker was isolated and excised from the wet SDS-PAGE gel and ligated into the pCR II vector to obtain a sufficient quantity of DNA for sequencing. We confirmed the expected biomarker by EcoRI digestion of the ligated vector pCR II (Figure 2). Out of the 30 white colonies, only 8 possessed the expected polymorphic biomarker, as determined by its relative movement when compared to the molecular weight marker. The nucleotide sequence of the biomarker was GCCCGTGCATAACACAAAAGAAATTGTCTAGAAA ACACAAAGTACAAGAGCATAGTACTGTTAACACTA TTAGCATGTACACAGTCAGTGAAAAAGCATACCCA TTAGCCCTTTCTCCCTGGTGTTGGCATTTATTCTAC TGCTTATTATAAGTGGTGATTTAGGGCCTGTGTAG GGAATATCAAGAAGTCTCTAAATTTGATAGTCACC AGTATTCAAAACCTTTCCTGAGAATTGACATACTA ATTTATACAGCACGGGC.

The biomarker sequence was analyzed by Genbank database account and revealed that the gene was significantly 


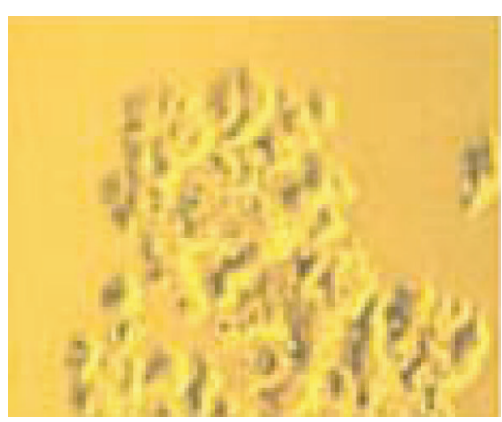

(a) MCF-7 (control)

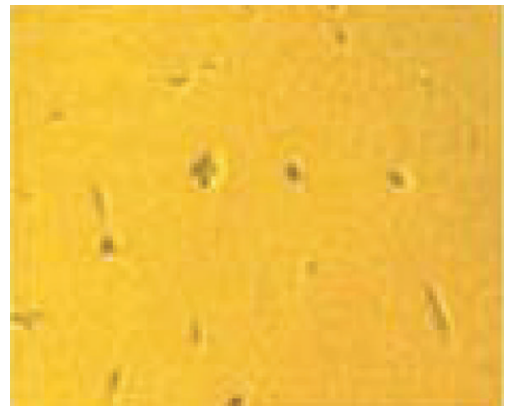

(b) MCF-10A

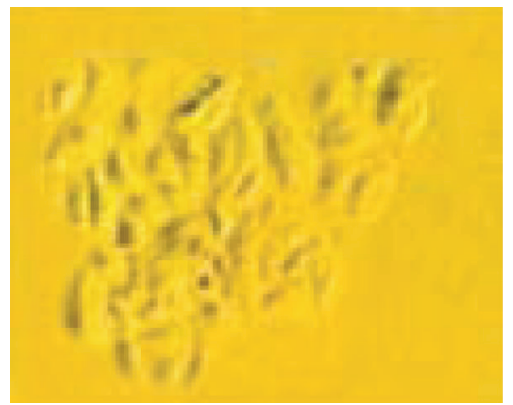

(c) Transfected MCF-7 cells

FIGURE 3: Cell morphology of MCF-7 cells transfected with the 262 bps polymorphic biomarker gene. MCF-7 cells were transfected with the 262 bps polymorphic marker gene using CELLFECTIN reagent-DNA complexes. The cells were incubated for 24 hours at $37^{\circ} \mathrm{C}$ in a $\mathrm{CO}_{2}$ incubator. The DNA-containing medium was replaced with $4 \mathrm{~mL}$ of growth medium (supplemented with serum) and the cells were incubated $\left(37^{\circ} \mathrm{C}\right)$ in a $\mathrm{CO}_{2}$ incubator for 48 hours. The cells were trypsinized, and the genomic DNA was isolated by DNAzol genomic DNA isolation reagent. Visualization of the cells was performed using Axiovert-25 inverted microscope (Software: Axiovision 4.0).

aligned with the nucleotide sequence of human chromosome 12 BAC RP11-476D10 (bps 19612-19353) with 100\% homology. The nucleotide sequence of the gene that was used for possible protein translate indicated that the gene codes for hypothetical protein XF2620.

In order to evaluate the effects that the $262 \mathrm{bps}$ biomarker would have on the morphology of MCF-7 cells, the MCF-7 cells were transfected with the $262 \mathrm{bps}$ biomarker. There were observable changes in the morphology of the transfected cells. For example, the transfected cells were more elongated and less aggregated (Figure 3 ).

\section{DISCUSSION}

The polymorphic biomarker with a nucleotide sequence of 262 bps was present in the genomic DNA of human mammary epithelial cell line MCF-10A. A single arbitrary and short oligonucleotide primer (A25 (GCCCGTGC)) was used in a DAF PCR reaction that produced about 50 amplification products. The selection of this primer was random because there is no record of any known DAF primer that works using human mammary epithelial cells. A detailed analysis of the amplification products showed that this polymorphic gene was absent from the genomic DNA of breast cancer cell line, MCF-7. The genomic difference between normal epithelial and breast cancer cell lines is most likely due to the deletion of the biomarker gene from the breast cancer cell genome. The absence of this gene in the genome of MCF-7cells may contribute significantly to its carcinogenic phenomena. The Genbank database analysis of the nucleotide sequence of the polymorphic marker (Genbank account: AC079630) revealed that alignment of this gene has $100 \%$ homology with the nucleotide sequence of chromosome 12 BAC RP11-476D10 from bps 19612 to 19532.

Analysis of this marker by Genbank CDS indicated that the sequence produces an alignment significantly similar to hypothetical protein XF2620. The XF2620 protein can be found on the distal end of chromosome 12. Previous reports have mentioned that the DNA architectural factor HMGA2 of chromosome 12 participates in a wide spectrum of tumors. This DNA architectural factor is located in or near the break point region of chromosome 12 [21]. The deletion of our polymorphic biomarker from chromosome 12 of normal human epithelial cells may trigger the loss of control the cell has over mitotic cell division, therefore generating abnormalities within the normal cell. We were curious as to the effects that the 262 bps biomarker would have when transfected into the genome of MCF-7 cells. The transfection experiment resulted in increased elongation and less aggregation of the MCF-7 cells. It is most likely that the insertion of the 262 bps gene may have silenced some of the genes responsible for tumorigenesis in MCF-7 cells.

It is our hope that in future studies, we will test the potential of our DAF primer on human breast cancer solid tissue.

\section{ACKNOWLEDGMENT}

This work was supported by the NIH/NHLBI Grant No KO1HL03835, the MBRS/RISE Grants No R25GM60414 and P20CA91366.

\section{REFERENCES}

[1] Watkins PC. Restriction fragment length polymorphism (RFLP): applications in human chromosome mapping and genetic disease research. BioTechniques. 1988;6(4):310-322.

[2] Donis-Keller H, Green P, Helms C, et al. A genetic linkage map of the human genome. Cell. 1987;51(2):319-337.

[3] Landegren U, Kaiser R, Caskey CT, Hood L. DNA diagnostics: molecular techniques and automation. Science. 1988; 241(4876):229-237.

[4] Caetano-Anollés G, Bassam BJ, Gresshoff PM. DNA amplification fingerprinting using very short arbitrary oligonucleotide primers. BioTechnology. 1991;9(6):553-557.

[5] Golenberg EM, Giannasi DE, Clegg MT, et al. Chloroplast DNA sequence from a Miocene Magnolia species. Nature. 1990;344(6267):656-658. 
[6] Hagelberg E, Gray IC, Jeffreys AJ. Identification of the skeletal remains of a murder victim by DNA analysis. Nature. 1991;352(6334):427-429.

[7] Kerangueven F, Noguchi T, Coulier F, et al. Genome-wide search for loss of heterozygosity shows extensive genetic diversity of human breast carcinomas. Cancer Research. 1997; 57(24):5469-5474.

[8] Jiang F, Desper R, Papadimitriou CH, et al. Construction of evolutionary tree models for renal cell carcinoma from comparative genomic hybridization data. Cancer Research. 2000; 60(22):6503-6509.

[9] Gatenby RA, Frieden BR. Application of information theory and extreme physical information to carcinogenesis. Cancer Research. 2002;62(13):3675-3684.

[10] Spencer VA, Samuel SK, Davie JR. Altered profiles in nuclear matrix proteins associated with DNA in situ during progression of breast cancer cells. Cancer Research. 2001;61(4):13621366.

[11] Kuller LH. The etiology of breast cancer from epidemiology to prevention. Public Health Reviews. 1995;23(2):157-213.

[12] Ernster VL, Barclay J, Kerlikowske K, Grady D, Henderson C. Incidence of and treatment for ductal carcinoma in situ of the breast. Journal of the American Medical Association. 1996;275(12):913-918.

[13] Wen WH, Bernstein L, Lescallett J, et al. Comparison of TP53 mutations identified by oligonucleotide microarray and conventional DNA sequence analysis. Cancer Research. 2000;60(10):2716-2722.

[14] Cotton RGH. Slowly but surely towards better scanning for mutations. Trends in Genetics. 1997;13(2):43-46.

[15] Bassam BJ, Caetano-Anollés G, Gresshoff PM. Fast and sensitive silver staining of DNA in polyacrylamide gels. Analytical Biochemistry. 1991;196(1):80-83.

[16] Osborne C, Wilson P, Tripathy D. Oncogenes and tumor suppressor genes in breast cancer: potential diagnostic and therapeutic applications. The Oncologist. 2004;9(4):361-377.

[17] Waldman FM, DeVries S, Chew KL, Moore DH II, Kerlikowske $\mathrm{K}$, Ljung B-M. Chromosomal alterations in ductal carcinomas in situ and their in situ recurrences. Journal of the National Cancer Institute. 2000;92(4):313-320.

[18] O’Connell P, Pekkel V, Fuqua SAW, Osborne CK, Clark GM, Allred DC. Analysis of loss of heterozygosity in 399 premalignant breast lesions at 15 genetic loci. Journal of the National Cancer Institute. 1998;90(9):697-703.

[19] Williams JGK, Kubelik AR, Livak KJ, Rafalski JA, Tingey SV. DNA polymorphisms amplified by arbitrary primers are useful as genetic markers. Nucleic Acids Research. 1990; 18(22):6531-6535.

[20] Wood KV. Recent advances and prospects for use of beetle luciferases as genetic reporters. In: Stanley P, Kricka L, eds. Bioluminescence and Chemiluminescence: Current Status. Chichester, UK: John Wiley \& Sons; 1991:543-546.

[21] Quade BJ, Weremowicz S, Neskey DM, et al. Fusion transcripts involving HMGA2 are not a common molecular mechanism in uterine leiomyomata with rearrangements in 12q15. Cancer Research. 2003;63(6):1351-1358. 

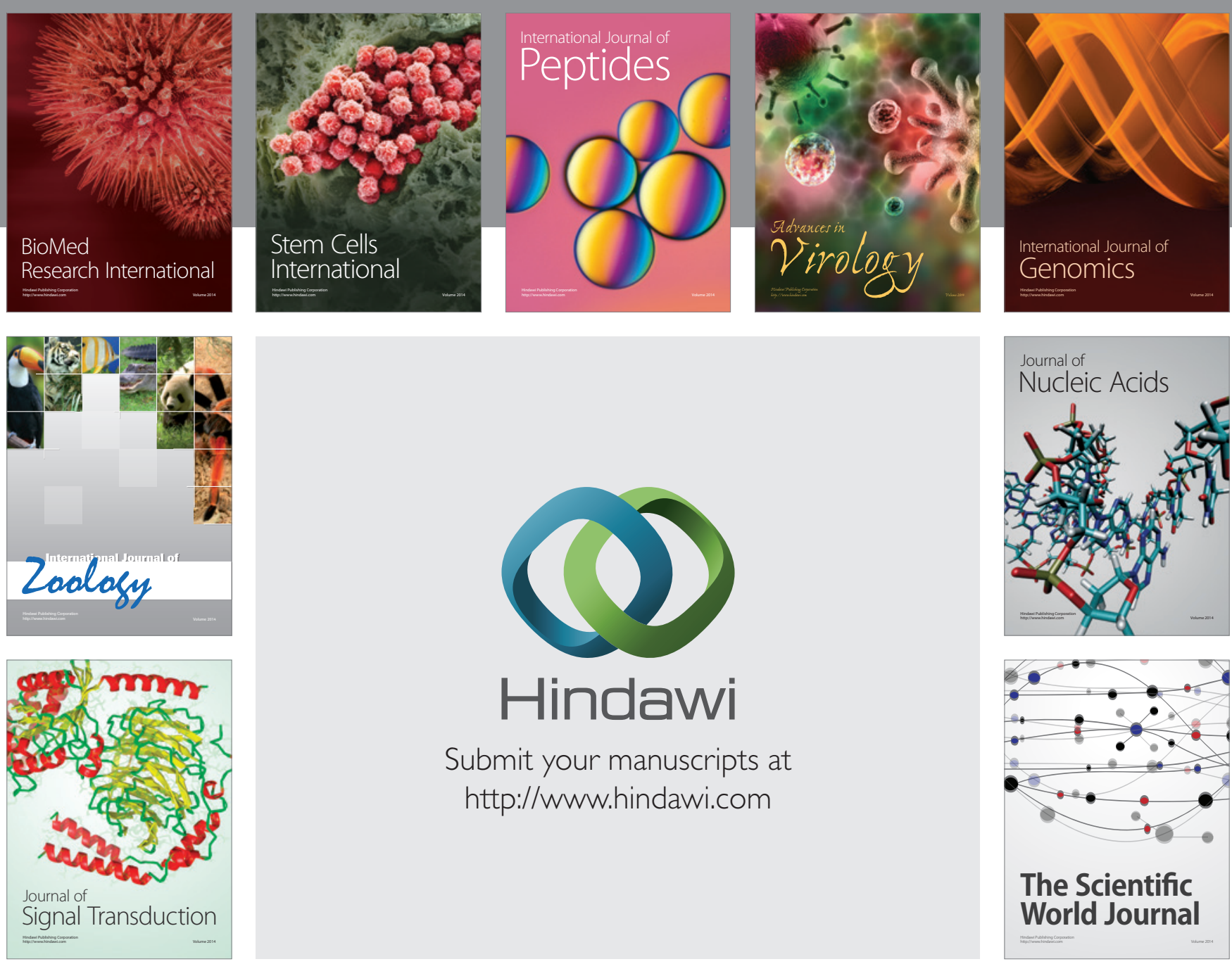

Submit your manuscripts at

http://www.hindawi.com
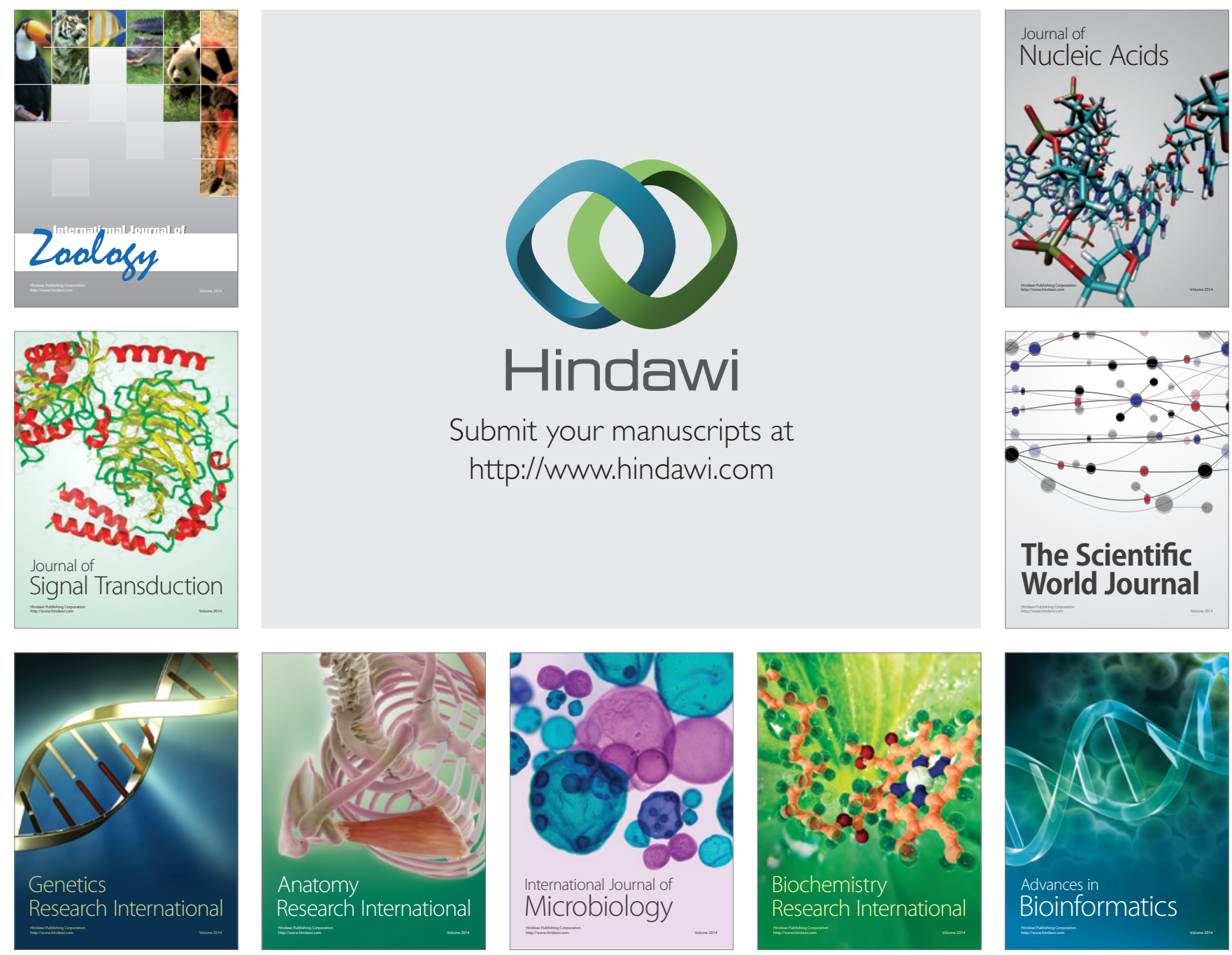

The Scientific World Journal
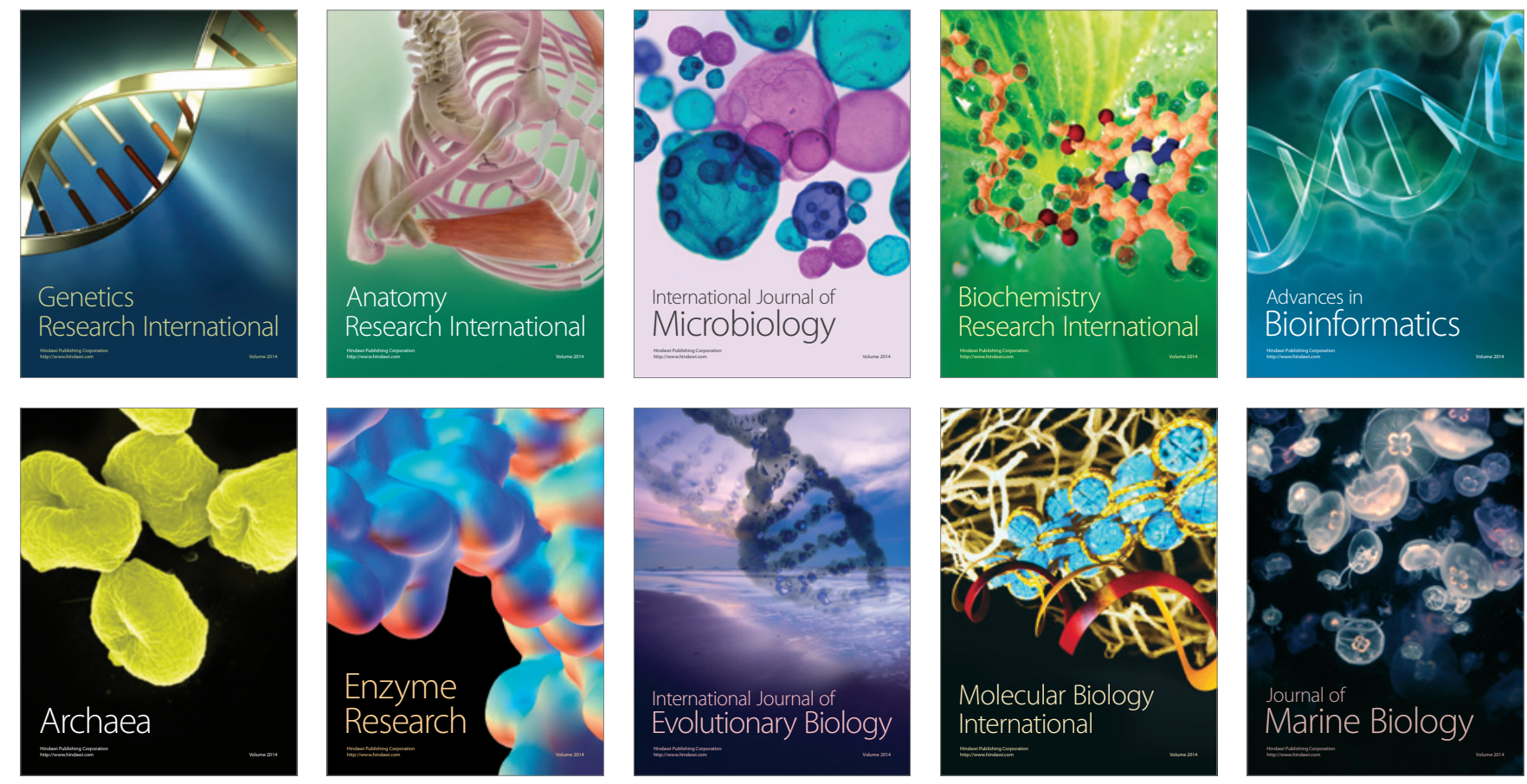